\title{
A Hybrid Perturbation and Morris Approach for Identifying Sensitive Parameters in Surface Water Quality Models
}

\author{
Y. T. Huang ${ }^{1}$ and L. Liu ${ }^{1,2, *}$ \\ ${ }^{I}$ Department of Civil and Resource Engineering, Dalhousie University, Halifax, NS B3J 1Z1, Canada \\ ${ }^{2}$ Energy and Environmental Research Center, North China Electric Power University, Beijing 102206, China
}

Received 3 May 2008; revised 20 November 2008; accepted 30 November 2008; published online 1 December 2008

\begin{abstract}
Surface water quality models (SWQM) are always developed as universal frameworks so that they can be flexibly employed to simulate a large variety of water bodies. These models are often over-parameterized (more parameters than needed are included in these models). As a result, it is necessary to identify sensitive parameters when these models are applied to the simulations of specific water bodies. Sensitivity analysis has been widely used as an effective tool to undertake the task. In this study, a hybrid approach was developed through integrating the parameter perturbation method and the Morris method into a general SWQMparameter sensitivity analysis framework. The approach was applied to Lake Maumelle in Arkansas with its hydrodynamics and water quality being simulated by the model CE-QUAL-W2. The sensitivities of the 96 model parameters were firstly evaluated by the parameter perturbation method in the simulation of the variables including temperature, ammonium, nitrate-nitrite, dissolved oxygen, total phosphorus and chlorophyll $a$, and 51 of them were found sensitive. The sensitivities of the 51 parameters were further investigated using the Morris method. It was found that each output variable was strongly sensitive to a distinctive set of parameters. It is also observed that the highly sensitive parameters display nonlinear relationships with the model outputs or strong correlations with other parameters. The obtained results from this study could provide a scientific base and solid start for the calibration, validation and application of the model.
\end{abstract}

Keywords: model parameters, Morris method, parameter perturbation; CE-QUAL-W2

\section{Introduction}

In the development of surface water quality models (SWQM), hydraulic and kinetic parameters are employed to describe mathematically the hydrodynamic and kinetic processes occurring in water bodies. These models are often established as universal frameworks in order that they are flexible and can be employed to simulate a large variety of water bodies. As a result, the developed universal SWQM frameworks always contain a large number of parameters. On the one hand, this could significantly facilitate and enhance the water quaility modeling process; on the other hand, inevitably, they are frequently over-parameterized (in other words, more parameters than needed are included in these models). Therefore, it becomes extremely necessary to identify the most important (or say, sensitive) parameters from the parameter pool in these models. Once identified, these parameters are the ones to which most of the calibration effort should be devoted. Previously, sensitivity analysis has been widely used as an effective tool for identifying the parameters that have relatively significant

*Corresponding author. Tel.: +1 902 4943958; fax: +1 9024943108.
E-mail address: Lei.Liu@dal.ca (L. Liu).

ISSN: 1726-2135 print/1684-8799 online

(C) 2008 ISEIS All rights reserved. doi:10.3808/jei.200800133 influences on the model output. In addition, sensitivity analysis can play an important role in model verification and application. It also can be used to provide insights into the robustness of model results when making decisions.

There are a large number of methods that can be used to perform a sensitivity analysis. These methods can be divided into two main categories: local and global sensitivity methods. Local sensitivity methods, such as the parameter perturbation method (Chapra, 1997) and differential analysis, calculate the local gradients of the model output with respect to infinitesimal parameter variations. They are simple to implement, computationally cheap and best suited for preliminary parameter screening to filter important parameters from the large number of model parameters. However, these techniques focus on the impact of changes from pre-specified parameter values (such as default values). They cannot evaluate the sensitivity of the parameters over their entire feasible ranges. Consequently, a number of global sensitivity analysis techniques have been developed and are receiving considerable attention by different modelers. Examples include Fourier amplitude sensitivity test (FAST) (Deflandre et al., 2006), regional sensitivity analysis (RSA) (Sincock et al., 2003), generalized sensitivity analysis (GSA) (Cox and Whitehead, 2005), adjoint sensitivity method (Piasecki, 2004) and Monte Carlo analysis (Bobba et al., 1996). They are capable of explaining the mo- 
del behavior under simultaneous parameter perturbations of arbitrary magnitude. Unfortunately, the global methods are generally computationally demanding (i.e. requiring a large number of model executions); their applications are mostly limited to the models that are computationally cheap or have a small number of parameters to be calibrated. Thus, for the computationally expensive water quality models, sensitivity analysis methods that are computational cheap are desired.

The Morris method is a relatively computationally cheap method for sensitivity analysis (Morris, 1991; Saltelli et al., 2004). Although it is a "one parameter at a time" (OAT) method, in which only one parameter is modified between two successive runs of the model, it can examine the entire range of a parameter in successive runs. In this sense, the method can be regarded as global (Saltelli et al., 2004). This method has been used in several fields, such as chemical kinetic systems (Zádor et al., 2006), watershed model (Francos et al., 2003; Griensven et al., 2006), climate change prediction (Campolongo and Braddock, 1999) and laboratory ground water flow and solute transport modeling (Larsbo and Jarvis, 2006).

CE-QUAL-W2 is a widely used hydrodynamic and water quality model supported by the USACE Waterways Experiments Station (Cole and Wells, 2003). Various sensitivity analyses have been conducted to investigate the sensitivities of different parameters in this model (Green, 2001; Bowen and Hieronymus, 2003; Cole and Wells, 2003; Wu et al., 2006). However, a complete sensitivity analysis for all parameters in CE-QUAL-W2 has never been performed before due to the facts that the model contains a vast number of adjustable parameters and that the model execution is highly computationally demanding. A complete sensitivity analysis would be a time-consuming process and computational challenge.

The objective of this study is to develop a hybrid approach based on the parameter perturbation method and the Morris method to perform a comprehensive sensitivity analysis for the hydraulic and kinetic parameters in the model CE-QUALW2. The developed approach is applied to Lake Maumelle in Arkansas (US) and it is indicated that the obtained results could provide a scientific base and solid start for the calibration, validation and application of the model.

\section{Methodology - The Hybrid Approach}

In the SWQM, model parameters are used to define various inherent hydrodynamic and kinetic processes affecting water flow and water quality. Some of the model parameters have significant impacts on the model outputs while others have less or no effects. Therefore, it is essential to screen and rank the parameters with respect to their sensitivities (on model output/behavior), and generate a short-list of most sensitive parameters so as to reduce the computation demand in model calibration, validation and application. In the proposed hybrid approach, the parameter perturbation method is simple to implement and computationally economic. It can help identify and eliminate the least sensitive ones from the general parameter pool through adjusting parameters from default values and analyzing their impacts. Then, the Morris method comes into play through ranking the remaining sensitive parameters in terms of their sensitivity levels and relative importance. Thus, individual groups of most and less-most sensitive parameters can be identified, allowing the modeler concentrate on them and calibrate the model in a more effective and efficient fashion.

\subsection{The Parameter Perturbation Method}

The parameter perturbation method is a "one-parameterat-a-time" approach. It consists of varying each of the model parameters within their feasible ranges at one point in the parameter hyperspace while holding all other terms unchanged (Melching and Yoon, 1996; Chapra, 1997). The corresponding variations of model variables reflect how sensitive the model outputs (or solutions) are in response to the changed parameter. Different statistic methods, such as the absolute error, relative error, absolute mean error (AME), and root mean square difference (RMSD) can be used to measure the variations. In this study, RMSD was used, which can be mathematically expressed as:

$$
\begin{aligned}
\operatorname{RMSD}= & \left\{\frac { 1 } { M } \sum _ { k = 1 } ^ { M } \left[y_{k}\left(x_{1}, \ldots, x_{i-1}, x_{i}+\Delta x_{i}, x_{i+1}, \ldots, x_{N}\right)\right.\right. \\
& \left.\left.-y_{k}\left(x_{1}, \ldots, x_{i-1}, x_{i}, x_{i+1}, \ldots, x_{N}\right)\right]^{2}\right\}^{1 / 2}
\end{aligned}
$$

where $y_{k}$ is the $k$ th model output (solution); $x_{i}$ refers to the $i$ th model parameter; $N$ is the total number of parameters; $\Delta x_{i}$ is the perturbation of the model parameter $x_{i}$ and $M$ is the total number of model outputs. A RMSD threshold was set for indicating whether the model parameter $x_{i}$ is sensitive or not.

\subsection{The Morris Method}

The Morris method was used in this study to rank the parameters in the parameter subset screened from the perturbation method. This method ranks the input parameters in terms of their relative importance and sensitivities through examining their mean effect on output and their non-linear interaction effects (Saltelli et al., 2004). This method was described below.

Assume that the model output $y=y(\mathbf{x})$ is a scalar function of the vector $\mathbf{x}$ of input parameters. The vector $\mathbf{x}=\left(x_{1}, x_{2}, \ldots\right.$, $\left.x_{N}\right)$ has $N$ elements and each $x_{i}$ is scaled to have values in the set $\{0,1 /(p-1), 2 /(p-1), \ldots, 1\}$, where $p$ is the number of levels. A model run is performed based on the random selection of all input parameters from the set $\{0,1 /(p-1), \ldots, 1-$ $\Delta\}$. And then a single input parameter, $x_{i}$, is randomly selected and modified by an increment $\Delta$, and a second run is performed. The elementary effect of the $i$ th element of $\mathbf{x}$ on the output $y$ where $x_{i}$ has been changed by an increment $\Delta$ can be calculated by:

$d\left(x_{i}\right)=\left[y\left(x_{1}, \ldots, x_{i-1}, x_{i}+\Delta, x_{i+1}, \ldots, x_{N}\right)-y(\mathbf{x})\right] / \Delta$

where $d\left(x_{i}\right)$ denotes the elementary effect of input parameter $i$ 
on the model output. In the case where a SWQM produces simulated outputs at several locations in a water body for a series of time points, the elementary effect of the $i$ th element of $\mathbf{x}$ on the outputs can be calculated using the following equation:

$$
\begin{aligned}
d\left(x_{i}\right)= & \frac{1}{M} \sum_{k=1}^{M} \frac{1}{\Delta}\left[y_{k}\left(x_{1}, \ldots, x_{i-1}, x_{i}+\Delta x_{i}, x_{i+1}, \ldots, x_{N}\right)\right. \\
& \left.-y_{k}\left(x_{1}, \ldots, x_{i-1}, x_{i}, x_{i+1}, \ldots, x_{N}\right)\right]
\end{aligned}
$$

where $M$ is the total number of simulated outputs at all locations and time points. Through the same procedure, the elementary effects of all elements of $\mathbf{x}$ (all parameters) can be obtained. However, this procedure is extremely computationally demanding, and thus becomes unaffordable for most water quality models. Instead, the Morris method tends to obtain a finite distribution of elementary effects associated with the model parameters, during which this procedure is repeated until stable output statistics, including (arithmetic) mean and standard deviation of elementary effects for each input parameter have been achieved.

In the above method, two model runs are required for evaluating each elementary effect. The computational effort required for obtaining $R$ elementary effects for each of $N$ input parameters equals to a total of $2 N R$ model runs. Morris suggested a more efficient sampling method. The sampling method starts by randomly selecting a "base" value $\mathbf{x}^{*}$. Each component $x_{i}$ of $\mathbf{x}^{*}$ is sampled from the set $\{0,1 /(p-1), 2 /(p-1), \ldots, 1\}$. Note that the vector $\mathbf{x}^{*}$ is used to generate the other sampling points but it is not one of them and the model is never evaluated at $\mathbf{x}^{*}$. The first sampling point, $\mathbf{x}^{(1)}$, is obtained by increasing or decreasing $i$ th element of $\mathbf{x}^{*}$ by $\Delta$. The second sampling point is generated from $\mathbf{x}^{*}$ but differs from $\mathbf{x}^{(1)}$ in its $i$ th element. The third sampling point, $\mathbf{x}^{(3)}$, is generated from the base value $\mathbf{x}^{*}$ but differs from $\mathbf{x}^{(2)}$ for element $j$ (for any $j \neq i$ ). The sampling method proceed to produce a succession of $(N+$ 1) sampling points $\mathbf{x}^{(1)}, \mathbf{x}^{(2)}, \ldots, \mathbf{x}^{(N+1)}$, in which two consecutive points differ in only one element. These sampling points defines a trajectory in the input space. In this sampling method, every element of the base vector $\mathbf{x}^{*}$ has been selected at least once to be increased or decreased by $\Delta$ in order to calculate one elementary effect for each parameter. The total computational effort required for obtaining $R$ elementary effects for each of $N$ input parameters equals $(N+1) R$ model runs. Although the sampling points belonging to the same trajectory are not independent, the $R$ elementary effects for each input parameter are from different trajectories and are independent. The Morris measure, $\mu\left(x_{i}\right)$, can then be used to estimate the overall effect of the $i$ th element of $\mathbf{x}$ on the outputs by the following equation:

$$
\mu\left(x_{i}\right)=\frac{1}{R} \sum_{j=1}^{R} d_{j}\left(x_{i}\right)
$$

where $d_{j}\left(x_{i}\right)$ represents the elementary effect of $x_{i}$ on the output $y$ in the $j$ th run, where $j=1, \ldots, R ; \mu\left(x_{i}\right)$ represents the mean of $d_{j}\left(x_{i}\right)$ over $R$ runs. And the standard deviation is given by:

$\sigma\left(x_{i}\right)=\sqrt{\sum_{j=1}^{R}\left[d_{j}\left(x_{i}\right)-\mu\left(x_{i}\right)\right]^{2} / R}$

where $\sigma\left(x_{i}\right)$ represents the standard deviation of $d_{j}\left(x_{\mathrm{i}}\right)$.

One potential problem associated with the Morris measure $\left[\mu\left(x_{i}\right)\right]$ lies in that, the calculated $d_{j}\left(x_{i}\right)$ might be positive or negative and the total effect measure could be biased or underestimated somehow because of that. To overcome this limitation, the Morris measure is modified to the following formula by using the absolute mean effect across $R$ runs instead:

$\mu^{*}\left(x_{i}\right)=\sum_{j=1}^{R}\left|d_{j}\left(x_{i}\right)\right| / R$

where $\mu^{*}\left(x_{i}\right)$ represents the absolute mean of $d_{j}\left(x_{i}\right)$ over $R$ runs, indicating the influence of input parameter $x_{i}$ on the model outputs; the larger the $\mu^{*}\left(x_{i}\right)$ is, the higher influence on the outputs from the input parameter $x_{i}$, and the more sensitive the parameter is.

The $\sigma\left(x_{i}\right)$ gives the spread extent of the elementary effect of one parameter on the output for all runs. A large measure of spread [large $\sigma\left(x_{i}\right)$ ] usually is contributed from either a highly non-linear impact of the parameter $x_{i}$ on the output, or an interaction of the parameter $x_{i}$ with other parameters, or both. On the contrary, a low $\sigma$ indicates similar values of the elementary effects across the different calculations, implying that the effects of $x_{i}$ are almost independent of the points in the input space at which they are computed and the values taken by other parameters.

The Morris method is easy to implement and computationally economic in that the number of model evaluations is linear to the number of input parameters. The method uses incremental ratios as the sensitivity measure (i.e. the elementary effect) which is apparently a local measure. In order to make it be a global measure, the final measure (elementary effect, $\left.\mu^{*}\right)$ is obtained by averaging several elementary effects at different points in the respective ranges of different input parameters. Thus, it does not depend on individual points at which the elementary effects are computed. In this sense, the method can be regarded as global (Saltelli et al., 2004).

\subsection{CE-QUAL-W2 Model}

CE-QUAL-W2 is a two dimensional, longitudinal/vertical, hydrodynamic and water quality model coded in Fortran (Cole and Wells, 2003). Because the model assumes lateral homogeneity, it is best suited for relatively long and narrow water bodies exhibiting longitudinal and vertical water quality gradients.

The model has the capability of simulating hydrodynamic and kinetic processes in water-bodies. Hydrodynamic calculations include predictions of water surface elevations, velocities and temperature. Any combination of constituents can be in- 
(a)
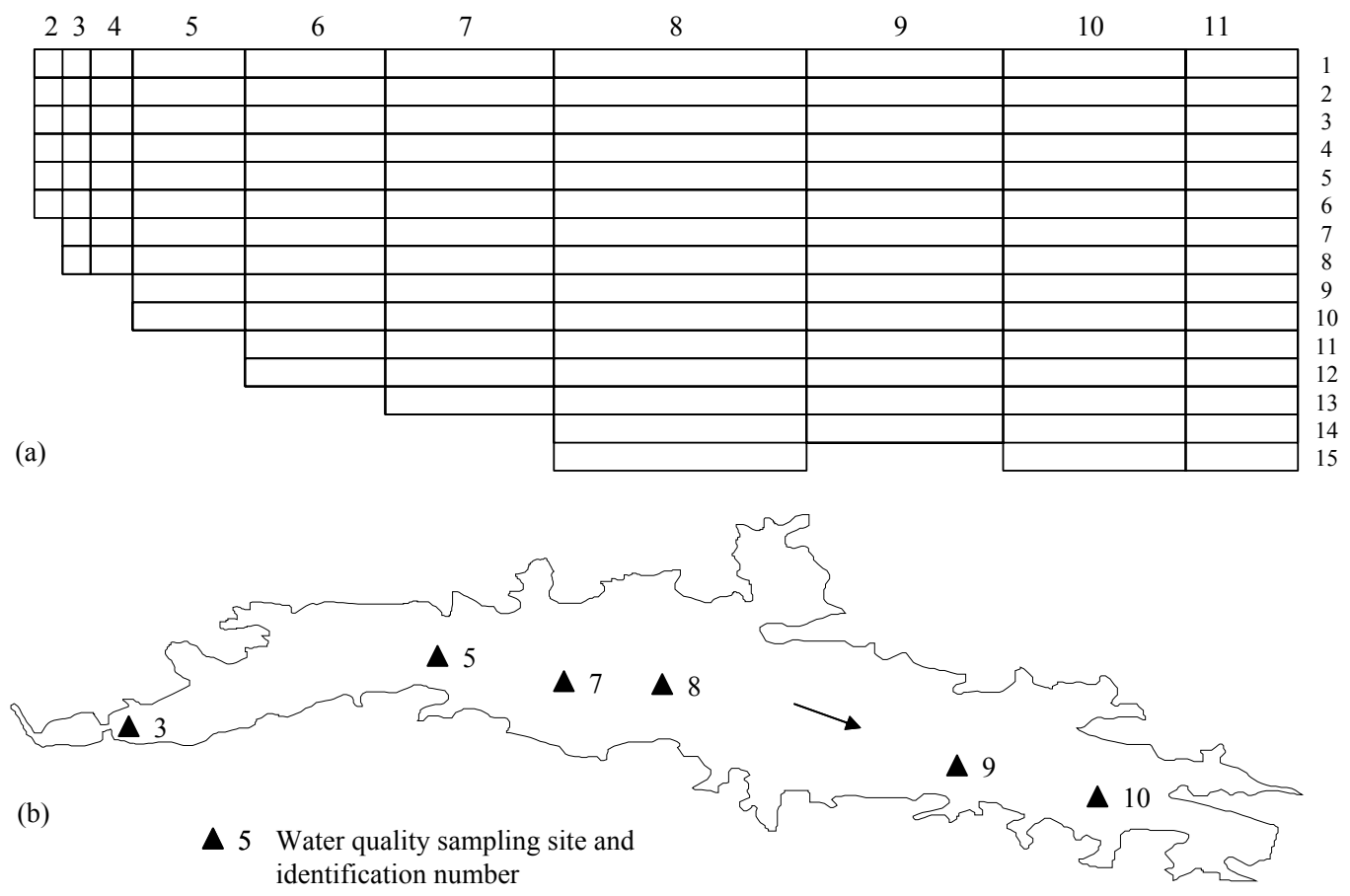

Figure 1. The Lake Maumelle and the computational grid: (a) the computational grid on the longitudinal-vertical plane; (b) Lake Maumelle with the water quality sampling sites.

cluded/excluded from a simulation. The water quality algorithm is modular allowing various constituents to be easily added as additional subroutines. A number of water quality state variables and derived variables can be simulated to form the outputs of the model. The model has been applied to rivers, lakes, reservoirs, estuaries, and combinations thereof, such as the Bluestone Reservoir in West Virginia (Tillman and Cole, 1994) and the Cumberland River, Tennessee (Thackston et al., 1994).

\section{The Study Site and Model Implementation}

\subsection{The Study Site}

In this study, the CE-QUAL-W2 model was applied to simulating the hydrodynamic process and water quality conditions in Lake Maumelle in Arkansas (Figure 1). The lake is the major drinking-water supply source for the Little Rock metropolitan area in central Arkansas. In addition to water supply, the reservoir is a habitat for wildlife and also used for recreational and fishing purposes. The lake contains a total water volume of $2.70 \times 10^{8} \mathrm{~m}^{3}$ at the spillway elevation and has a volume of $2.31 \times 10^{8} \mathrm{~m}^{3}$ of usable water (Green, 2001). Its surface area at the spillway elevation is approximately $36 \mathrm{~km}^{2}$. maximum length of the reservoir is $19 \mathrm{~km}$, and maximum depth is $13.7 \mathrm{~m}$ with an average depth of $7.5 \mathrm{~m}$. Four fixed sampling sites (Figure 1) were established along the downstream gradient of Lake Maumelle. Water quality measured in Lake Maumelle varied spatially and temporally. Total phosphorus concentrations were significantly less in the lower end of the lake than that in the upper end of the lake; however, concentrations of nitrogen, orthophosphorus, total and dissolved organic carbon did not vary significantly along the reach of the lake. The chlorophyll $a$ concentrations varied seasonally, with the highest concentrations occurred in October and November, but were relatively uniformly distributed throughout the space and year.

\subsection{Model Implementation}

To set up the CE-QUAL-W2 model, Lake Maumelle was discretized into 10 active computational segments along the mainstream of the reservoir with each segment being divided vertically into 1-m layers. The computational grid in the longitudinal/vertical plane is presented in Figure 1. It consists of 10 active longitudinal segments and up to 15 active cells in a segment.

The model was configured to simulate the hydrodynamics and water quality of Lake Maumelle for the time period of $2002 \sim 2004$. A large number of hydraulic and kinetic parameters, mainly kinetic parameters, are used in this model and 96 of them can be adjusted in the simulation of the hydrodynamic and water quality variables, including temperature, dissolved oxygen (DO), ammonium $\left(\mathrm{NH}_{4}\right)$, nitrate plus nitrite $\left(\mathrm{NO}_{3}+\mathrm{NO}_{2}\right)$, total phosphorus (TP) and chlorophyll $a$ (Chla). These parameters were preliminarily calibrated to the lake situations, based mostly on the suggestions provided by Cole and Wells (2003). The pre-calibrated parameter values, as well as the names and definitions of the parameters were presented in Appendix. In addition, the upper and lower bounds of the parameters were also provided in this Appendix. These bounds were determined according to the literature, particularly Cole 
and Wells (2003) and were adjusted to ensure the numerical stability of the model.

\section{Results and Discussions}

\subsection{Sensitive Parameters}

A sensitivity analysis for the 96 dynamic and kinetic parameters in the simulations of temperature, $\mathrm{DO}, \mathrm{NH}_{4}, \mathrm{NO}_{3}+$ $\mathrm{NO}_{2}$, TP and Chla was conducted using the parameter perturbation method. This purpose was accomplished by implementing two operations for each parameter. Firstly, the value of a selected parameter was increased from its preliminarily calibrated value by $10 \%$ of its range (difference between its upper and lower bounds) while holding all other parameters to their preliminarily calibrated values without change. Secondly, the value of the selected parameter was decreased by $10 \%$ of its range from its preliminarily calibrated value. The corresponding variations of model output for each hydrodynamic or water quality variable were calculated using equation (1). If one of the two operations resulted in a RMSD value greater than a certain number for a variable $(0.1 \%$ of averaged observed values for temperature, and $0.5 \%$ for the other variables in this study), it can be considered that this parameter was sensitive in the simulation of this variable. This process was continued until the effects of all parameters were investigated.

In total, 51 parameters were found sensitive in the simulations of temperature and concentrations of $\mathrm{NH}_{4}, \mathrm{NO}_{3}+\mathrm{NO}_{2}$, DO, TP and Chla over the time period of $2002 \sim 2004$, as presented in Table 1. In addition, the results show that hydraulic parameters, including AX, DX and FRICT, were sensitive in the simulation of water quality variables, while a part of kinetic parameters were sensitive in the simulation of temperature. Based on the results, the other 45 parameters are much less sensitive or not sensitive at all in the simulations of these variables. The values of these parameters could remain as their preliminarily calibrated values throughout the model calibration and application process with very minor impacts on the model results.

\subsection{Most Sensitive Parameters}

The sensitivities of the 51 parameters that were identified by the parameter perturbation method were further investigated using the Morris method. In the Morris method, how to choose the value of $p$ is a challenging question. The value of $p$ depends not only on the sampling step $\Delta$, which can be expressed as $\Delta=p / 2(p-1)$ (Saltelli et al., 2004), but also on the sample size, $R$. When the sample size $R$ is small, it is very likely that not all the possible parameter levels be explored; while a high value of $R$ implies a bigger sample size and certainly more model runs. Morris (1991) used a sample size of $R=4$ as the minimum value to place confidence in the results. Previous experiments (Campolongo and Saltelli, 1997; Campolongo et al., 1999; Saltelli et al., 2000) demonstrated that the choice of $p=4$ and $R=10$ produced valuable results. In this study, $p=4$ and a much bigger $R(R=30)$ were used to make sure that stable results could be achieved (the order of parameters would not change with the increase of the sampl- ing size $R$ ). In total, 1560 model evaluations $[=R \times(N+1)=$ $30 \times(51+1)=1560]$ were performed. The sensitivity ranks of the 51 parameters in the simulations of temperature and concentrations of $\mathrm{NH}_{4}, \mathrm{NO}_{3}+\mathrm{NO}_{2}, \mathrm{DO}, \mathrm{TP}$, and Chla over the years of $2002 \sim 2004$ were presented and discussed in the following context.

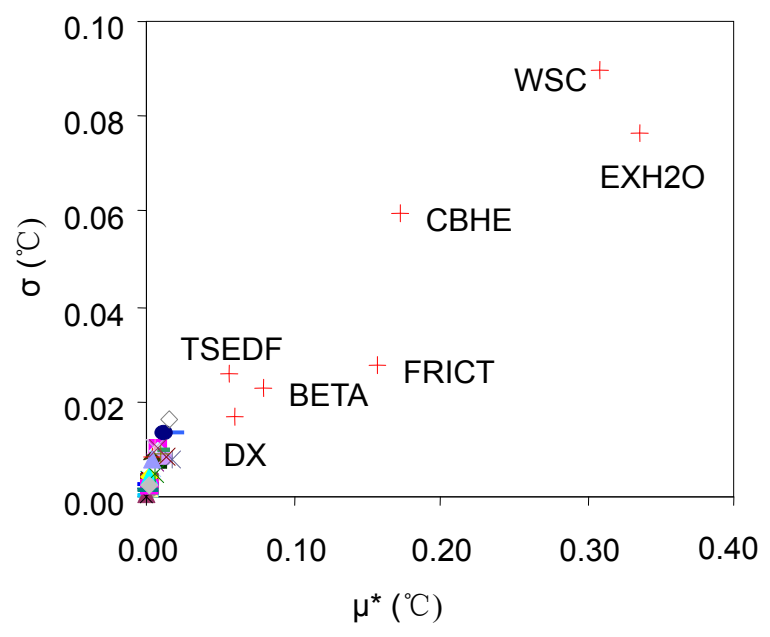

Figure 2. The Morris sensitivity measures $\mu^{*}$ and $\sigma$ for the 51 parameters in the simulation of temperature (only the most sensitive parameters are labeled).

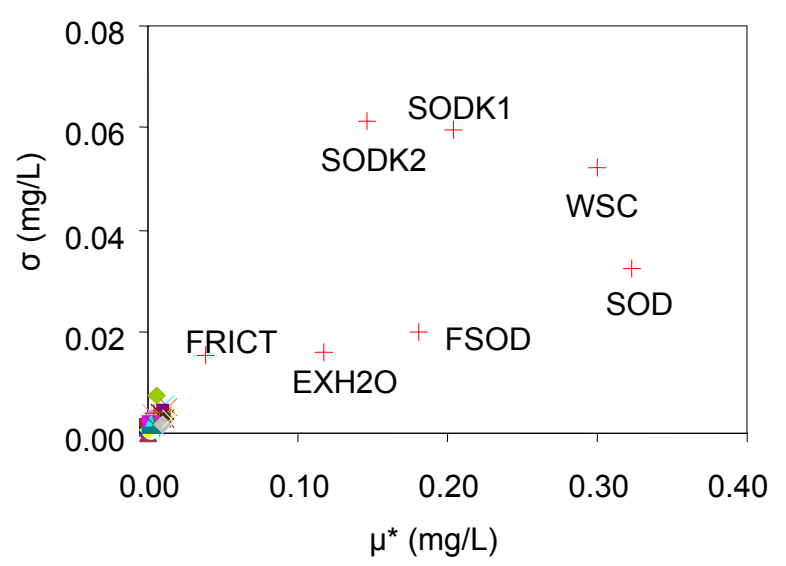

Figure 3. The Morris sensitivity measures $\mu^{*}$ and $\sigma$ for the 51 parameters in the simulation of DO (only the most sensitive parameters are labeled).

\section{(1) Temperature}

The Morris sensitivity measures $\mu^{*}$ (averaged absolute elementary effect) and $\sigma$ (standard deviation of elementary effects) were plotted in Figure 2 for the 51 model parameters in the simulation of temperature. It can be seen that the parameters can be categorized into three groups. Group one consists of three parameters, WSC, EXH2O, and CBHE, and all of them have high values of $\mu^{*}$ and $\sigma$. High $\mu^{*}$ indicates their significant impacts on the simulated temperature. High $\sigma$ indicates that these parameters may have either nonlinear relationships with the simulated temperature or interactions with other parame- 
ters or both. In other words, the influences of these parameters on the simulated temperature would change as the values of these parameters vary or the values of other parameters change. Group two includes four parameters, i.e., FRICT, BETA, DX and TSEDF. Their variations also affect the simulated temperature. The above seven parameters are the most sensitive parameters in simulating the temperature in the lake. Group three consists of the other 44 parameters. Their means and standard deviations of elementary effects are low, implying that the variations of their values result in minor influences on the simulated temperature.

\section{(2) DO}

Figure 3 shows the Morris sensitivity measures $\mu^{*}$ and $\sigma$ for the 51 model parameters in the simulation of DO. Seven parameters that have significant effects on the simulated DO are distinguished from other parameters. These parameters are SOD, WSC, SODK1, FSOD, SODK2, EXH2O, and FRICT. Among them, SOD and WSC are the most important parameters in terms of $\mu^{*}$. SODK1 and SODK2 have high values of both $\mu^{*}$ and $\sigma$, indicating that they have large influence on simulated DO and their influence depends on their values and/ or the values of other parameters. FSOD, EXH2O and FRICT are also important in the simulation of DO.

\section{(3) $\mathrm{NH}_{4}$}

The Morris sensitivity measures $\mu^{*}$ and $\sigma$ for the 51 model parameters in the simulation of $\mathrm{NH}_{4}$ is presented in Figure 4. It can be seen that 15 parameters have effects on the simulation of $\mathrm{NH}_{4}$. These parameters are NH4DK, NH4R, ALGP, NH4K1, EXH2O, AR, AG, PO4R, SOD, OMK1, ALGN, AHSP, ASAT, FSOD, and SODK2. It can also be found that most of the parameters with high values of $\mu^{*}$ also have high values of $\sigma$. It is indicated that the parameters that have large influences on simulated $\mathrm{NH}_{4}$ also have high non-linear relationships with simulated $\mathrm{NH}_{4}$ and/or have high interactions with other parameters.

\section{(4) $\mathrm{NO}_{3}+\mathrm{NO}_{2}$}

Figure 5 shows the Morris sensitivity measures $\mu^{*}$ and $\sigma$ for the 51 model parameters in the simulation of $\mathrm{NO}_{3}+\mathrm{NO}_{2}$. As shown, 51 parameters can be divided into four groups. ALGP is the most sensitive parameter in the simulation of $\mathrm{NO}_{3}+\mathrm{NO}_{2}$ because of its high average of absolute elementary effects. Its standard deviation is also high, indicating that its sensitivity strongly depends on its own value and the values of other parameters. The second group is composed of PO4R and SOD, both of which have a high average of absolute elementary effects and a high standard deviation. The third group consists of approximately a dozen of parameters. The influences of these parameters on the simulation of $\mathrm{NO}_{3}+\mathrm{NO}_{2}$ can not be neglected. The remaining parameters form the fourth group. These parameters have the lowest means and standard deviations of elementary effects, implying that they have small influences on the simulation of $\mathrm{NO}_{3}+\mathrm{NO}_{2}$.
Table 1. 51 Sensitive Parameters Identified by the Perturbation Method

\begin{tabular}{|c|c|c|c|c|c|c|c|}
\hline \# & Parameter & $\mathrm{T}^{*}$ & $\mathrm{NH}_{4}$ & $\begin{array}{l}\mathrm{NO}_{3} \\
+\mathrm{NO}_{2}\end{array}$ & $\mathrm{DO}$ & $\mathrm{TP}$ & Chla \\
\hline 1 & $\mathrm{AE}$ & + & + & + & & + & + \\
\hline 2 & $\mathrm{AG}$ & & + & + & & + & + \\
\hline 3 & AHSN & & + & + & & + & + \\
\hline 4 & AHSP & + & + & + & + & + & + \\
\hline 5 & AK1 & & + & + & & + & + \\
\hline 6 & $\mathrm{AK} 2$ & & + & + & & + & + \\
\hline 7 & AK3 & & + & + & & + & \\
\hline 8 & $\mathrm{AK} 4$ & & & + & & & \\
\hline 9 & ALCHLA & & & & & & + \\
\hline 10 & ALGN & + & + & + & & + & + \\
\hline 11 & ALGP & + & + & + & + & + & + \\
\hline 12 & ALPOM & & + & + & & + & \\
\hline 13 & $\mathrm{AM}$ & + & + & + & + & + & + \\
\hline 14 & AR & + & + & + & + & + & + \\
\hline 15 & AS & + & + & + & & + & + \\
\hline 16 & ASAT & & + & + & & + & + \\
\hline 17 & $\mathrm{AX}$ & & + & + & & + & \\
\hline 18 & BETA & + & + & + & & + & + \\
\hline 19 & $\mathrm{CBHE}$ & + & + & + & + & + & + \\
\hline 20 & DX & + & + & + & & + & + \\
\hline 21 & EXH2O & + & + & + & + & + & + \\
\hline 22 & EXOM & + & + & + & + & + & + \\
\hline 23 & EXSS & + & + & + & & + & + \\
\hline 24 & FI & + & + & + & & + & + \\
\hline 25 & FRICT & + & + & + & + & + & + \\
\hline 26 & FSOD & & + & + & + & + & + \\
\hline 27 & LDOMDK & & + & + & + & + & + \\
\hline 28 & LPOMDK & + & + & + & & + & + \\
\hline 29 & LRDDK & & + & + & & + & \\
\hline 30 & LRPDK & & & + & & & \\
\hline 31 & NH4DK & + & + & + & + & + & + \\
\hline 32 & NH4K1 & & + & + & & + & \\
\hline 33 & NH4K2 & & + & + & & + & \\
\hline 34 & NH4R & + & + & + & + & + & + \\
\hline 35 & NO3DK & & + & + & & + & + \\
\hline 36 & NO3K1 & & & + & & & \\
\hline 37 & NO3K2 & & & + & & & \\
\hline 38 & NO3S & & + & + & & + & \\
\hline 39 & O2LIM & & + & + & & + & \\
\hline 40 & OMK1 & + & + & + & + & + & + \\
\hline 41 & OMK2 & & + & + & & + & \\
\hline 42 & PO4R & + & + & + & + & + & + \\
\hline 43 & POMS & & + & + & & + & + \\
\hline 44 & RDOMDK & + & + & + & & + & + \\
\hline 45 & RPOMDK & & + & + & & + & \\
\hline 46 & SEDK & & + & + & & + & \\
\hline 47 & SOD & & + & + & + & + & + \\
\hline 48 & SODK1 & & + & + & + & + & + \\
\hline 49 & SODK2 & & + & + & & + & + \\
\hline 50 & TSEDF & + & + & + & & + & + \\
\hline 51 & WSC & + & + & + & + & + & + \\
\hline
\end{tabular}




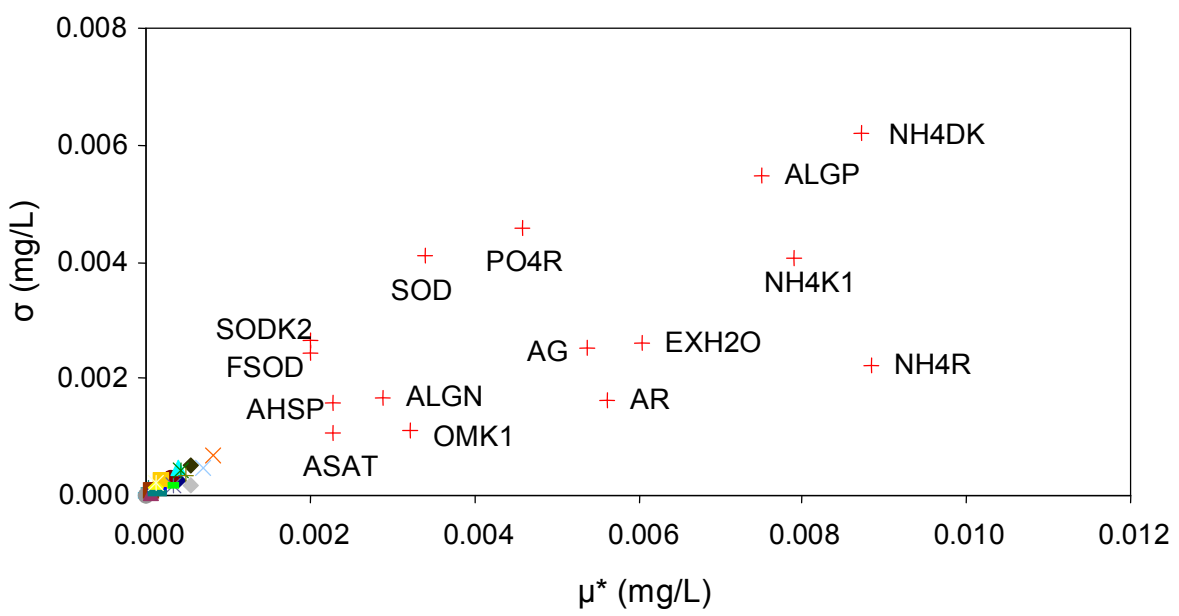

Figure 4. The Morris sensitivity measures $\mu^{*}$ and $\sigma$ for the 51 parameters in the simulation of $\mathrm{NH}_{4}$ (only the most sensitive parameters are labeled).

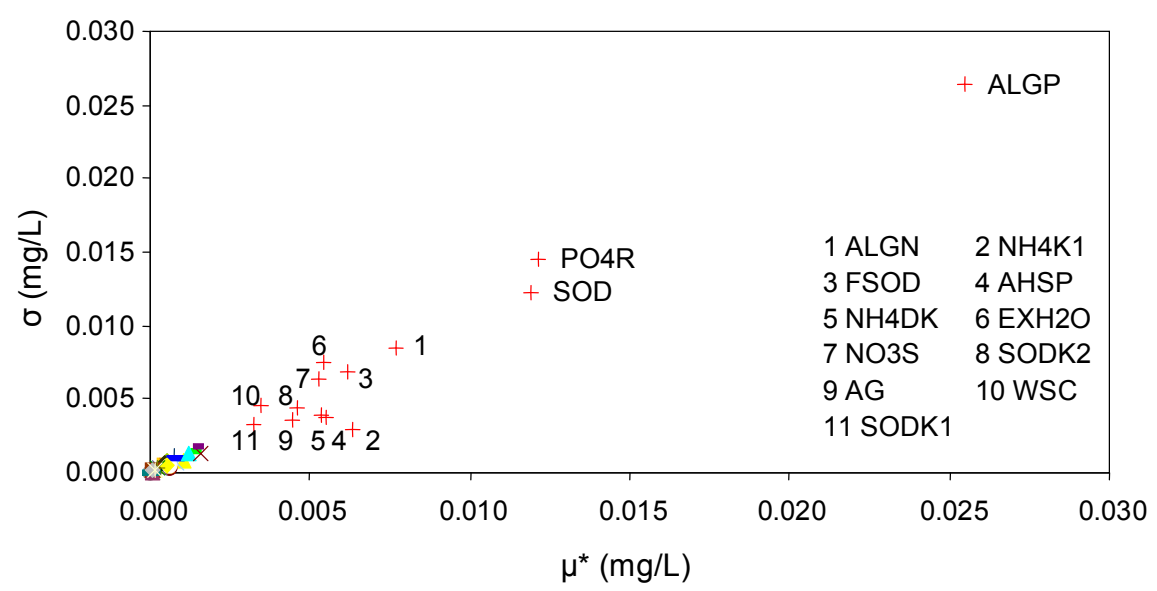

Figure 5. The Morris sensitivity measures $\mu^{*}$ and $\sigma$ for the 51 parameters in the simulation of $\mathrm{NO}_{3}+\mathrm{NO}_{2}$ (only the most sensitive parameters are labeled).

\section{(5) TP}

Figure 6 presents the sensitivity measures $\mu^{*}$ and $\sigma$ for the 51 parameters in the simulation of TP. It can be found that the parameters can be divided into four groups. The first group consists of only one parameter, PO4R. This parameter has the highest mean and standard deviation of elementary effects. The second group is composed of six parameters, SOD, ALGP, FSOD, SODK2, SODK1, and WSC. These parameters have relative high means and standard deviations of elementary effects. The third group includes three parameters, EXH2O, RDOMDK and ALGN. The remaining parameters have low means and standard deviations of elementary effects, indicating minor influences from them on the simulated concentration of TP.

\section{(6) Chla}

Figure 7 shows the Morris sensitivity measures $\mu^{*}$ and $\sigma$ for the 51 model parameters in the simulation of Chla. 20 parameters which have been identified as "most sensitive para- meters" in the simulation of Chla can be further ranked based on the values of calculated absolute mean of elementary effects. Among them, AS is in the first place; ALGP is in the second place; ALGN, PO4R and SOD are in the third place; RDOMDK is in the fourth place; and all others are in the sixth place.

\section{(7) Summary}

Apparently, simulation of each model variable (i.e. temperature, $\mathrm{NH}_{4}, \mathrm{NO}_{3}+\mathrm{NO}_{2}, \mathrm{DO}, \mathrm{TP}$ and Chla in this case study) is sensitive to a different set of parameters, respectively. Based on the mean absolute elementary effect $\left(\mu^{*}\right)$ and standard deviation of elementary effects $(\sigma)$, the most sensitive parameters were determined. A total of 28 parameters were identified as most sensitive parameters when simulating all the model variables, as presented in Table 2. Therefore, the significance of conducting model sensitivity analysis becomes immediately obvious from the perspective of improving the forthcoming modeling effort when the parameters could be narrowed from a number of 96 to 28 . 


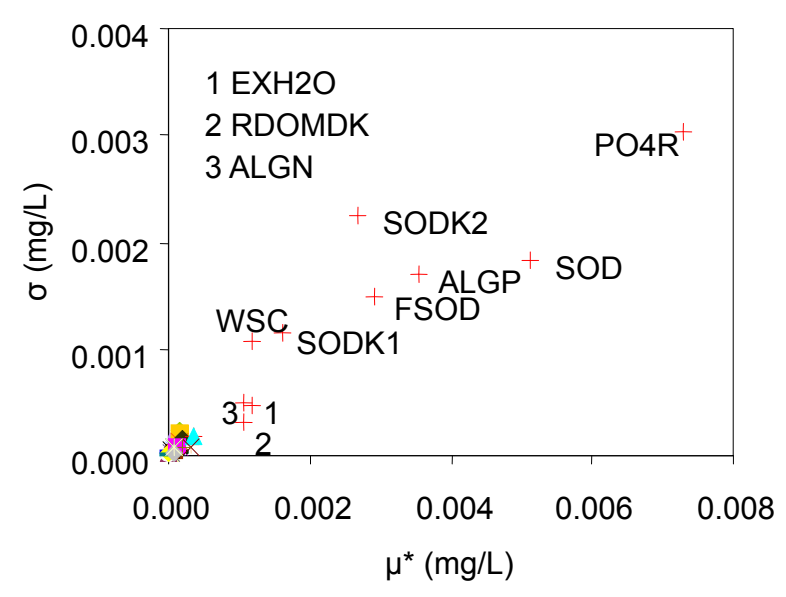

Figure 6. The Morris sensitivity measures $\mu^{*}$ and $\sigma$ for the 51 parameters in the simulation of TP (only the most sensitive parameters are labeled).

Table 2. The Most Sensitive Parameters Identified by the Morris Method in the Simulation of Temperature, $\mathrm{NH}_{4}$, $\mathrm{NO}_{3}+\mathrm{NO}_{2}$, DO, TP and Chla

\begin{tabular}{ll}
\hline Variable & Most Sensitive Parameters \\
\hline Temperature & EXH2O, WSC, CBHE, FRICT, BETA, DX, \\
& TSEDF \\
DO $^{*}$ & SOD, WSC, SODK1, FSOD, SODK2, EXH2O, \\
& FRICT \\
$\mathrm{NH}_{4}{ }^{*}$ & NH4R, NH4DK, NH4K1, ALGP, EXH2O, AR, \\
& AG, PO4R, SOD, OMK1, ALGN, AHSP, ASAT, \\
& FSOD, SODK2 \\
$\mathrm{NO}_{3}+\mathrm{NO}_{2}{ }^{*}$ & ALGP, PO4R, SOD, ALGN, NH4K1, FSOD, \\
& NH4DK, EXH2O, AHSP, NO3S, SODK2, AG, \\
& WSC, SODK1 \\
& PO4R, SOD, ALGP, FSOD, SODK2, SODK1, \\
& WSC, EXH2O, RDOMDK, ALGN \\
$\mathrm{Ch}^{*}$ & AS, ALGP, SOD, ALGN, PO4R, RDOMDK, AM, \\
& ALCHLA, AG, FSOD, LPOMDK, AHSP, OMK1, \\
& SODK2, EXH2O, AR, NH4R, SODK1, WSC \\
Overall ${ }^{* *}$ & AG, AHSP, ALCHLA, ALGN, ALGP, AM, AR, \\
& AS, ASAT, BETA, CBHE, DX, EXH2O, FRICT, \\
& FSOD, LPOMDK, NH4DK, NH4K1, NH4R, \\
& NO3S, OMK1, PO4R, RDOMDK, SOD, SODK1, \\
& SODK2, TSEDF, WSC \\
\hline *The parameters are ranked in terms of importance given by $\mu{ }^{*}$. \\
**The parameters are ordered alphabetically.
\end{tabular}

\section{Conclusions}

This study presents a computationally economic and efficient approach for identifying sensitive parameters in SWQMs. This approach was developed through integrating the parameter perturbation method and the Morris method into a general SWQM-parameter sensitivity analysis framework. The approach was applied to the model CE-QUAL-W2 which was set up to simulate the hydrodynamics and water quality in Lake Maumelle in Arkansas. Model parameters were firstly evaluated by the parameter perturbation method and were then further investigated using the Morris method. It was found by the parameter perturbation that 51 out of 96 parameters were sensitive in the simulations of the variables including temperature, ammonium, nitrate-nitrite, dissolved oxygen, total phosphorus and chlorophyll $a$. The results from the parameter perturbation method show that hydraulic parameters are sensitive in the simulation of water quality, while some kinetic parameters are important in the simulation of hydrodynamics. It is thus indicated that hydrodynamic calibration and water quality calibration should be implemented simultaneously. By the Morris method, it was found that the simulation of each variable was strongly sensitive to a different subset of 51 parameters and 28 out of the 51 parameters were found the most sensitive parameters in the simulations of all the variables. It is also observed through the Morris method that the highly sensitive parameters not only display nonlinear relationships with the model outputs but also demonstrate strong interactions with other parameters. This indicates that the importance of these sensitive parameters depends closely on the values of other parameters, and thereby all the sensitive parameters should be calibrated simultaneously in the next modeling step. The obtained results from this study could provide a scientific base and solid start for the calibration, validation and application of the model.

Acknowledgments. The authors would like to thank the Natural Science and Engineering Research Council of Canada for funding this research. This study was also supported by the Natural Science Foundation and the Major State Basic Research Development Program of China (50609008, 2005CB724200 and 2005CB724201). The authors are grateful to Dr. R. Zou, Tetra Tech, Inc. for providing data and technical suggestions, as well as to the editors and the anonymous reviewers for their insightful comments.

\section{References}

Bobba, A.G., Singh, V.P., and Bengtsson, L. (1996). Application of first-order and Monte Carlo analysis in watershed water quality models, Water Resour. Manage., 10, 219-240, doi:10.1007/BF0042 4204.

Bowen, J.D., and Hieronymus, J.W. (2003). A CE-QUAL-W2 Model of Neuse Estuary for Total Maximum Daily Load Development, $J$. Water Resour. Plann. Manage., 129(4), 283-294, doi:org/10.1061/ (ASCE)0733-9496(2003)129:4(283).

Campolongo, F., and Braddock, R. (1999). Sensitivity analysis of the IMAGE Greenhouse model, Environ. Model. Software, 14, $275-$ 282, doi:10.1016/S1364-8152(98)00079-6.

Campolongo, F., and Braddock, R. (1999). The use of graph theory in the sensitivity analysis of the model output: a second order screening method, Reliability Engineering and System Safety, 64, 1-12, doi:10.1016/S0951-8320(98)00008-8.

Campolongo, F., and Saltelli, A. (1997). Sensitivity analysis of an environmental model: an application of different analysis methods, Reliability Engineering and System Safety, 57(1), 49-69, doi:10.10 16/S0951-8320(97)00021-5.

Campolongo, F., Tarantola, S., and Saltelli, A. (1999). Tackling quantitatively large dimensionality problems, Computer Physics Communications, 117, 75-85.

Chapra, S.C. (1997). Surface Water-Quality Modeling, McGRAWHILL Company, INC., New York.

Cole, T.M., and Wells, S.A. (2003). CE-QUAL-W2: A Two-Dimensio nal, Laterally Averaged, Hydrodynamic and Water Quality Model, Version 3.2, Instruction Report EL-03-1, US Army Engineering 


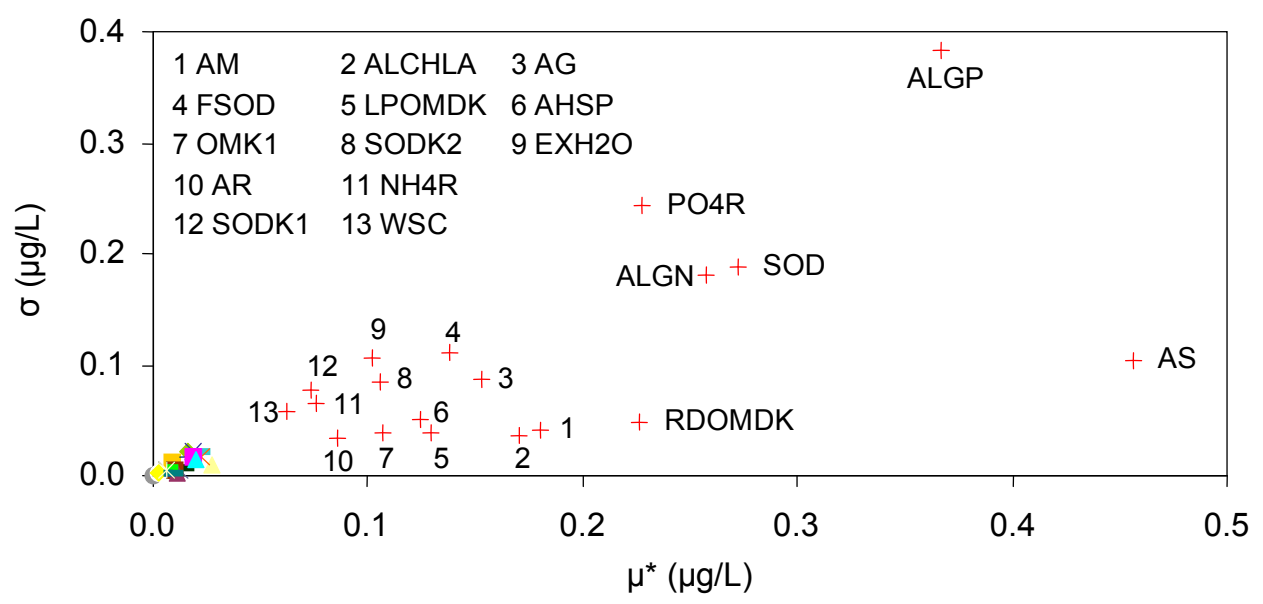

Figure 7. The Morris sensitivity measures $\mu^{*}$ and $\sigma$ for the 51 parameters in the simulation of Chla (only the most sensitive parameters are labeled).

and Research Development Center, Vicksburg, MS.

Cox, B.A., and Whitehead, P.G. (2005). Parameter sensitivity and predictive uncertainty in a new water quality model, Q2, $J$. Environ. Eng., 131(1), 147-157, doi:10.1061/(ASCE)0733-9372(2 005)131:1(147).

Deflandre, A., Williams R.J., Elorza, F.J., Mira , J., and Boorman, D.B. (2006). Analysis of the QUESTOR water quality model using a Fourier amplitude sensitivity test (FAST) for two UK Rivers, Sci. Total Environ., 360, 290-304.

Francos, A., Elorza, F.J., Bouraoui, F., Bidoglio, G., and Galbiati, L. (2003). Sensitivity analysis of distributed environmental simulation models: understanding the model behaviour in hydrological studies at the catchment scale, Reliability Engineering and System Safety, 79, 205-218, doi:10.1016/S0951-8320(02)00231-4.

Green, W.R. (2001). Analysis of ambient conditions and simulation of hydrodynamics, constituent transport, and water-quality characteristics in Lake Maumelle, Arkansas, 1991-92, Water-Resources Investigations Report 01-4045, U.S. Geological Survey.

Griensven, A. van, Meixner, T., Grunwald, S., Bishop, T., Diluzio, M., and Srinivasan, R. (2006). A global sensitivity analysis tool for the parameters of multi-variable catchment models, J. Hydrol., 324, 10-23, doi:10.1016/j.jhydrol.2005.09.008.

Larsbo, M., and Jarvis, N. (2006). Information content of measurements from tracer microlysimeter experiments designed for parameter identification in dual-permeability models, J. Hydrol., 325, 273-287, doi:10.1016/j.jhydrol.2005.10.020.

Melching, C.S., and Yoon, C.G. (1996). Key sources of uncertainty in QUAL2E model of Passaic River, J. Water Resour. Plann. Manage., 122(2), 105-113, doi:org/10.1061/(ASCE)0733-9496(19 96)122:2(105).

Morris, M.D. (1991). Factorial sampling plans for preliminary com- putational experiments, Technometrics, 33(2), 161-74, doi:10.2307 /1269043.

Piasecki, M. (2004). Optimal wasteload allocation procedure for achieving dissolved oxygen water quality objectives. I: sensitivity analysis, J. Environ. Eng., 130(11), 1322-1334, doi:org/10.1061/ (ASCE)0733-9372(2004)130:11(1322).

Saltelli, A., Tarantola, S., and Campolongo, F. (2000). Sensitivity analysis as an ingredient of modeling, Statistical Science, 15(4), 377-395.

Saltelli, A., Tarantola, S., Campolongo, F., and Ratto, R. (2004). Sensitivity Analysis in Practice: a Guide to Assessing Scientific Models, John Wiley \& Sons Ltd, Chichester.

Sincock, A.M, Wheater, H.S., and Whitehead, P.G. (2003). Calibration and sensitivity analysis of a river water quality model under unsteady flow conditions, J. Hydrol., 277, 214-29, doi:10.1016/S0 022-1694(03)00127-6.

Thackston, E.L., Speece, R.E., Adams, W.R., and Cardozo, R. (1994). Modeling the effects of combined sewer overflows from Nashville on the Cumberland River, Proceedings of the Water Environmental Federation Annual Conference and Exposition, Chicago, IL, 123134.

Tillman, D.H., and Cole, T.M. (1994). Bluestone phase 2 temperature and dissolved oxygen modeling study, Environmental Lab., Army Engineer Waterways Experiment Station, Vicksburg, MS, USA.

Wu, J., Zou, R., and Yu, S.L. (2006). Uncertainty Analysis for Coupled Watershed and Water Quality Modeling Systems, J. Water Resour. Plann. Manage., 132, 5, 351-361, doi:10.1061/(ASCE)073 3-9496(2006)132:5(351).

Zádor, J., Zsély, I. Gy., and Turányi, T. (2006). Local and global uncertainty analysis of complex chemical kinetic systems, Reliability Engineering and System Safety, 91, 1232-1240.

Appendix I. Definitions of the 51 Sensitive Parameters

\begin{tabular}{|c|c|c|c|c|c|}
\hline \# & Parameter & $\begin{array}{l}\text { Pre-calibrated } \\
\text { Value }\end{array}$ & $\begin{array}{l}\text { Lower } \\
\text { Bound }\end{array}$ & $\begin{array}{l}\text { Upper } \\
\text { Bound }\end{array}$ & Definition \\
\hline 1 & $\mathrm{AE}$ & 0.020 & 0.014 & 0.030 & Maximum algal excretion rate, day $^{-1}$ \\
\hline 2 & $\mathrm{AG}$ & 1.800 & 1.500 & 2.200 & Maximum algal growth rate, day ${ }^{-1}$ \\
\hline 3 & AHSN & 0.014 & 0.010 & 0.020 & Algal half-saturation for $\mathrm{N}$ limited growth, $\mathrm{g} \mathrm{m}^{-3}$ \\
\hline 4 & AHSP & 0.002 & 0.001 & 0.004 & Algal half-saturation for $\mathrm{P}$ limited growth, $\mathrm{gm}^{-3}$ \\
\hline 5 & AK1 & 0.100 & 0.050 & 0.120 & Fraction of algal growth rate at lower temperature $\left(5^{\circ} \mathrm{C}\right)$ for algal growth \\
\hline 6 & AK2 & 0.990 & 0.975 & 0.990 & $\begin{array}{l}\text { Fraction of maximum algal growth rate at lower temperature }\left(27^{\circ} \mathrm{C}\right) \text { for } \\
\text { maximum algal growth }\end{array}$ \\
\hline 7 & AK3 & 0.990 & 0.980 & 0.999 & Fraction of maximum algal growth rate at upper temperature $\left(30^{\circ} \mathrm{C}\right)$ for \\
\hline
\end{tabular}




\begin{tabular}{|c|c|c|c|c|c|}
\hline & & & & & maximum algal growth \\
\hline 8 & AK4 & 0.100 & 0.080 & 0.180 & Fraction of algal growth rate at upper temperature $\left(40^{\circ} \mathrm{C}\right)$ for algal growth \\
\hline 9 & ALCHLA & 110.00 & 105.00 & 115.00 & Ratio between algal biomass and chlorophyll $a$ \\
\hline 10 & ALGN & 0.070 & 0.065 & 0.075 & Stoichiometric equivalent between algal biomass and nitrogen \\
\hline 11 & ALGP & 0.0025 & 0.0020 & 0.0030 & Stoichiometric equivalent between algal biomass and phosphorus \\
\hline 12 & ALPOM & 0.800 & 0.750 & 0.850 & $\begin{array}{l}\text { Fraction of algal biomass that is converted to particulate organic matter when } \\
\text { algae die }\end{array}$ \\
\hline 13 & $\mathrm{AM}$ & 0.070 & 0.065 & 0.075 & Maximum algal mortality rate, day $^{-1}$ \\
\hline 14 & AR & 0.070 & 0.050 & 0.100 & Maximum algal respiration rate, day ${ }^{-1}$ \\
\hline 15 & AS & 0.150 & 0.100 & 0.180 & Algal settling rate, $\mathrm{m} \mathrm{day}^{-1}$ \\
\hline 16 & ASAT & 80.00 & 60.00 & 86.00 & Light saturation intensity at maximum photosynthetic rate, $\mathrm{W} \mathrm{m}^{-2}$ \\
\hline 17 & $\mathrm{AX}$ & 1.000 & 0.500 & 5.000 & Longitudinal eddy viscosity, $\mathrm{m}^{2} \mathrm{~s}^{-1}$ \\
\hline 18 & BETA & 0.450 & 0.400 & 0.500 & Fraction of incident solar radiation absorbed at the water surface \\
\hline 19 & CBHE & 0.500 & 0.400 & 0.600 & Coefficient of bottom heat exchange, $\mathrm{W} \mathrm{m}^{-2} \mathrm{~s}^{-1}$ \\
\hline 20 & $\mathrm{DX}$ & 1.000 & 1.000 & 5.000 & Longitudinal eddy diffusivity, $\mathrm{m}^{2} \mathrm{~s}^{-1}$ \\
\hline 21 & EXH2O & 0.450 & 0.250 & 0.450 & Solar radiation extinction coefficient for pure water, $\mathrm{m}^{-1}$ \\
\hline 22 & EXOM & 0.100 & 0.010 & 0.200 & Solar radiation extinction coefficient due to organic suspended solids, $\mathrm{m}^{-1}$ \\
\hline 23 & EXSS & 0.100 & 0.080 & 0.120 & Solar radiation extinction coefficient due to inorganic suspended solids, $\mathrm{m}^{-1}$ \\
\hline 24 & FI & 0.010 & 0.001 & 0.030 & Interfacial friction factor \\
\hline 25 & FRICT & 65.0 & 60.0 & 80.0 & Chezy coefficient \\
\hline 26 & FSOD & 0.800 & 0.800 & 1.000 & Fraction of the zero-order SOD rate used. \\
\hline 27 & LDOMDK & 0.150 & 0.100 & 0.200 & Labile dissolved organic matter (DOM) decay rate, day ${ }^{-1}$ \\
\hline 28 & LPOMDK & 0.150 & 0.100 & 0.200 & Labile particulate organic matter (POM) decay rate, day ${ }^{-1}$ \\
\hline 29 & LRDDK & 0.001 & 0.001 & 0.005 & Labile to refractory DOM decay rate, day $^{-1}$ \\
\hline 30 & LRPDK & 0.001 & 0.001 & 0.005 & Labile to refractory POM decay rate, day ${ }^{-1}$ \\
\hline 31 & NH4DK & 0.050 & 0.030 & 0.080 & Ammonium decay rate, day ${ }^{-1}$ \\
\hline 32 & NH4K1 & 0.100 & 0.010 & 0.250 & Fraction of nitrification rate at lower temperature $\left(5^{\circ} \mathrm{C}\right)$ for ammonia decay \\
\hline 33 & NH4K2 & 0.990 & 0.970 & 0.990 & $\begin{array}{l}\text { Fraction of nitrification rate at lower temperature }\left(25^{\circ} \mathrm{C}\right) \text { for maximum } \\
\text { ammonia decay }\end{array}$ \\
\hline 34 & NH4R & 0.004 & 0.002 & 0.005 & $\begin{array}{l}\text { The sediment release rate of ammonium under anaerobic conditions, } \\
\text { specified as a fraction of SOD }\end{array}$ \\
\hline 35 & NO3DK & 0.050 & 0.030 & 0.150 & Nitrate decay rate, day ${ }^{-1}$ \\
\hline 36 & NO3K1 & 0.100 & 0.030 & 0.150 & Fraction of denitrification rate at lower temperature $\left(5^{\circ} \mathrm{C}\right)$ for nitrate decay \\
\hline 37 & NO3K 2 & 0.990 & 0.950 & 0.990 & $\begin{array}{l}\text { Fraction of denitrification rate at lower temperature }\left(25^{\circ} \mathrm{C}\right) \text { for maximum } \\
\text { nitrate decay }\end{array}$ \\
\hline 38 & NO3S & 0.000 & 0.000 & 0.020 & $\begin{array}{l}\text { Denitrification rate from sediments which represents how fast nitrate is } \\
\text { diffused into the sediments where it undergoes denitrification, }, \mathrm{m} \mathrm{day}^{-1}\end{array}$ \\
\hline 39 & O2LIM & 1.000 & 0.800 & 1.200 & $\begin{array}{l}\text { Dissolved oxygen half-saturation constant or concentration at which aerobic } \\
\text { processes are at } 50 \% \text { of their maximum, } \mathrm{g} \mathrm{m}^{-3}\end{array}$ \\
\hline 40 & OMK1 & 0.100 & 0.050 & 0.200 & $\begin{array}{l}\text { Fraction of organic matter decay rate at lower temperature }\left(5^{\circ} \mathrm{C}\right) \text { for organic } \\
\text { matter decay }\end{array}$ \\
\hline 41 & OMK2 & 0.990 & 0.990 & 0.999 & $\begin{array}{l}\text { Fraction of organic matter decay rate at upper temperature }\left(30^{\circ} \mathrm{C}\right) \text { for organic } \\
\text { matter decay }\end{array}$ \\
\hline 42 & PO4R & 0.001 & 0.001 & 0.002 & $\begin{array}{l}\text { Sediment release rate of phosphorus under anaerobic conditions specified as } \\
\text { a fraction of the sediment oxygen demand }\end{array}$ \\
\hline 43 & POMS & 0.300 & 0.250 & 0.350 & Particulate organic matter (POM) settling rate, $\mathrm{m} \mathrm{day}^{-1}$ \\
\hline 44 & RDOMDK & 0.002 & 0.001 & 0.002 & Refractory DOM decay rate, day ${ }^{-1}$ \\
\hline 45 & RPOMDK & 0.002 & 0.001 & 0.003 & Refractory POM decay rate, day ${ }^{-1}$ \\
\hline 46 & SEDK & 0.000 & 0.000 & 0.001 & Sediment decay rate, day ${ }^{-1}$ \\
\hline 47 & SOD & 1.100 & 0.800 & 1.200 & $\begin{array}{l}\text { Zero-order sediment oxygen demand for each segment in the computational } \\
\text { grid, } \mathrm{g} \mathrm{O}_{2} \mathrm{~m}^{-2} \text { day }^{-1}\end{array}$ \\
\hline 48 & SODK1 & 0.100 & 0.050 & 0.150 & $\begin{array}{l}\text { Fraction of SOD or sediment decay rate at lower temperature }\left(5^{\circ} \mathrm{C}\right) \text { for } \\
\text { zero-order SOD or first-order sediment decay }\end{array}$ \\
\hline 49 & SODK2 & 0.990 & 0.980 & 0.999 & $\begin{array}{l}\text { Fraction of SOD or sediment decay rate at upper temperature }\left(30^{\circ} \mathrm{C}\right) \text { for } \\
\text { zero-order SOD or first-order sediment decay }\end{array}$ \\
\hline 50 & TSEDF & 1.000 & 0.800 & 1.000 & $\begin{array}{l}\text { Coefficient that regulates how much short-wave solar radiation that } \\
\text { penetrates to the bottom of the grid is added back to water column }\end{array}$ \\
\hline 51 & WSC & 0.900 & 0.800 & 1.000 & $\begin{array}{l}\text { Wind-sheltering coefficient which is used to adjust measured wind speed at } \\
\text { met station to effective wind speed at water surface }\end{array}$ \\
\hline
\end{tabular}

